\title{
LUCES Y SOMBRAS. MEDIOS DE COMUNICACIÓN. VERANO DE 2008
}

\section{LIGHTS AND SHADOWS. MEDIA. SUMMER 2008}

Maribel Martínez Eder: Portavoz de FIATYR (Federación Ibérica de Telespectadores y Radioyentes) mm.eder@asociacionplazadelcastillo.org

\section{CURRÍCULUM VITAE}

Fundadora y presidenta de la Asociación Plaza del Castillo ATR Navarra de Usuarios de Medios de Comunicación, integrante de FIATYR (Federación Ibérica de Asociaciones de Telespectadores y Radioyentes). Fue miembro del Consejo Asesor de RTVE en Navarra.

\section{RESUMEN}

Se denuncia la desprotección del usuario en general y de los menores en particular en España, y la petición de una autoridad audiovisual independiente de todo poder partidista y mediático con poder sancionador. La comunidad europea da un ultimátum a España por superar límites de publicidad en televisión. Se exponen diferentes ejemplos de desprecio a los telespectadores.

\section{PALABRAS CLAVE}

Publicidad - Autoridad Audiovisual - Telespectador

\section{ABSTRACT}


It denounces the lack of protection of general user and minors in particular in Spain, and the request of an authority independent of any power audiovisual and media party with powers of sanction. The European Community gives an ultimatum to Spain to overcome limits of television advertising. Presents different examples of contempt for the viewers.

\section{KEY WORDS}

Advertising - Audiovisual Authority - Viewer

\section{TEXTO}

\section{$\underline{\text { Las Luces }}$}

El OCTA, Observatorio de Contenidos Televisivos y Audiovisuales, compuesto por 50 organizaciones de lo más representativo de la sociedad civil española del que la Asociación Plaza del Castillo de Usuarios de Medios de Comunicación forma parte, hizo público un comunicado, denunciando la desprotección del usuario en general y de los menores en particular en España, y la petición de una autoridad audiovisual independiente de todo poder partidista y mediático con poder sancionador. La jornada, lleno total, tuvo lugar el pasado 3 de Junio en la Universidad Complutense de Madrid.

La Vicepresidenta Sra. De la Vega durante su intervención ante la Comisión Constitucional en el Congreso de los Diputados, repasó las principales promesas socialistas relativas a los medios de comunicación, apostando por una Ley 
Audiovisual de "gran consenso" y la creación de un Consejo Superior de Medios Audiovisuales. Según la Sra. De la Vega la creación del Consejo servirá para garantizar los derechos de "ciudadanos, instituciones y medios de comunicación"

OFCOM, autoridad competente y regulador independiente de las telecomunicaciones en Reino Unido, ha multado a la cadena británica ITV, con 5,7 millones de libras, 7.2 millones de euros, por fraude en concursos telefónicos. La cadena recaudó 10 millones de euros por votos no contabilizados que afectaron a unos 10 millones de llamadas telefónicas. La multa supera la sanción impuesta al canal GMTV, multado el pasado mes de Septiembre con dos millones de libras (2,5 millones de euros), por un fraude similar.

Los tribunales de justicia de los países anglosajones actúan con mano dura ante los abusos. Las batallas legales por las capturas fotográficas de los "paparazzi" se multiplican en el Reino Unido y en los U.S.A., donde cada vez tienen más dificultades para violar la intimidad. Por unas fotos tomadas durante sus vacaciones, el actor Hugh Grant y su ex pareja Liz Hurley serán indemnizados con 58.000 libras (72.500 euros); la vista se celebró en el Tribunal Superior de Inglaterra y Gales.

La audiencia de Barcelona ha ordenado la apertura de juicio contra el actor Pepe Rubianes por ultraje a España, por unas declaraciones pronunciadas en un programa de TV3 televisión pública catalana: El programa era "El Club" y se emitió el 20 de Enero de 2006. Según informa la agencia EFE, ante las carcajadas del presentador, sus palabras fueron: "Que se vayan a tomar por el culo estos españoles, ojalá les exploten los cojones y vayan al cielo sus cojones, se vaya a la mierda la puta España"

La CE da un ultimátum a España por superar límites de publicidad en televisión. La pasada primavera la comisión Europea envió a España un dictamen motivado, por violar los límites de publicidad televisiva que impone la Directiva Europea de Televisión sin Fronteras. Un estudio reveló que "las mayores cadenas españolas de 
televisión públicas y comerciales, superan de largo y de forma regular el límite de 12 minutos por hora de anuncios y teletienda" "España no ha tomado las medidas necesarias para garantizar el respeto al límite europeo", censuró la comisaria europea de la Sociedad de la Información y Medios, la Sra. Viviane Reding: "Insto a las autoridades españolas a actuar con urgencia para ajustarse a la Directiva de Televisión sin Fronteras. De lo contrario, pediré a la Comisión que lleve el caso ante el Tribunal de Justicia de la U.E." El límite de 12 minutos contemplado en la legislación europea tiene por objetivo proteger al público del exceso de interrupciones publicitarias y promover un modelo televisivo europeo de calidad. En España la adaptación de 17 minutos en lugar de 12 integrando telepromoción y publireportaje se considera una violación grave. Cualquier otra interpretación es una falta de respeto a los espectadores y a los ciudadanos" Informa la agencia EFE.

Hace decenios que llevamos denunciando, la mayor presión publicitaria de Europa.

Protección de Datos (AEPD) con motivo de la presentación del Día de Internet el pasado 17 de Mayo, publicó una guía (PDF) dirigida a menores y a sus padres, con recomendaciones y consejos útiles sobre protección de datos en el entorno de Internet y para que naveguen de forma segura, a través de sencillas pautas. Su contenido remarca algunos consejos fundamentales, entre los que destacan la necesidad de consentimiento paterno si un menor de 14 años quiere colgar información privada en Internet, como perfiles o fotos.

\section{$\underline{\text { Las Sombras }}$}

Las expresiones de dolor de familiares y amigos de la familia Luyk-Torres por la muerte de su hijo Sergio, y de estupor hacia la sensacionalista prensa-televisiónbasura española. Lo más perverso es decir que la pedimos: 16 millones de espectadores, la máxima audiencia contabilizada; como viene siendo habitual, en un 
encuentro deportivo del máximo interés; la televisión basura, viernes y sábados en horas de máxima audiencia, en torno a 2.

Al parecer, el martes 1 de Julio al finalizar OT, Tele5 tiene previsto estrenar "La Caja Roja" de la productora catalana fundada en 1994 por LAVINIA TC, "La Fábrica de la Tele", responsable de Aquí hay tomate, Las gafas de Angelino, La Noria, Hormigas Blancas, El Ventilador, etc. No hace falta ser un lince para saber de que clase de contenido hablamos. Parece que personas encerradas viviendo al límite.

Aunque conocemos movimientos en algunos países sobre tan repugnante tema, nos faltaba conocer la iniciativa para la proclamación del "Día del Orgullo Pederasta" en una web accesible a todo el mundo, como se ha denunciado ante el Defensor del Pueblo. La progresión es alarmante: el doble de detenciones en lo que llevamos de año que en todo 2006, por ejemplo.

Durante el programa de Antena3 "El diario de Patricia" de boomerang tv., día si y día también, algunos participantes se levantan airados porque han sido engañados. Es sencillamente intolerable la burla, el desprecio a los participantes y por supuesto al espectador. El tuteo sistemático, el trato grosero por parte de la presentadora lo dice todo. Viernes 14 de Marzo de 2008, a eso de las 8 de la tarde, presenta Juan y Medio (diario y medio), que sustituye a la presentadora habitual de este "Museo de los horrores". El presentador, gran humorista: "ya estoy muy mayor para hacer estos programas" (totalmente de acuerdo), mientras un señor le dice que lo que más atrae de él es "mi miembro": y el 'presentador: "explícate sin que nos cierren la cadena" y el señor: "El primer día nos fuimos a vivir juntos, para que no se me escape , soy padre adoptivo del hijo de mi novio; sexualmente muy activo puedo con todo: hombres, mujeres, todo un surtido". 
Todavía no he reaccionado ante la impresión que me produjo escuchar por boca de una criatura: "tengo 9 años y no me gustan los programas porno", en la jornada del Octa referenciada. Los niños y adolescentes, en España, pueden acceder en abierto a programación pornográfica dura, y han presenciado innumerables situaciones de violencia y abuso: crímenes, violaciones, insultos; infinitamente más que relaciones relajadas, respetuosas entre los sexos, cariñosas, confortables, con valores, etc. No es extraño que algunos perciban las relaciones amorosas como un horror.

Cuarzo Producciones, la productora que creó Ana Rosa Quintana, responsable de lo que el excelente crítico televisivo José Javier Esparza llama con toda justicia "el desolladero de Antena3", ¿Dónde estás corazón?. El hecho de criticar en el programa que presenta en Tele5, algunas circunstancias del programa de Antena3, $i$ no supone un cinismo inadmisible creyendo que el espectador ignora la propiedad de la productora? ¿que opinaría de que Jaime Cantizano preguntase a la audiencia si desean ver sin pantalones, no al hijo de Ana García Obregón, sino al de la propietaria de la productora, Sra. Ana Rosa Quintana?

Pamplona-Madrid 26 de Junio de 2008. 